\begin{tabular}{|c|c|}
\hline European Association for the & $\begin{array}{c}\text { International Conference on Renewable Energies and Power Quality } \\
\text { (ICREPQ'12) }\end{array}$ \\
$\begin{array}{c}\text { Development of Renewable Energies, Environment } \\
\text { and Power Quality (EA4EPQ) }\end{array}$ & $\begin{array}{c}\text { Santiago de Compostela (Spain), 28th to 30th March, 2012 } \\
\end{array}$
\end{tabular}

\title{
A proposal for Computational Refunding Analysis based on real time disturbances measurements
}

\author{
I. N. Gondim ${ }^{1}$, C. E. Tavares ${ }^{1}$, J. A. F. Barbosa Jr. ${ }^{1}$, J. C. Oliveira ${ }^{1}$, A. Oliveira ${ }^{1}$, P. H. O. Rezende ${ }^{1}$ \\ ${ }^{1}$ Federal University of Uberlandia, Faculty of Electrical Engineering, Av. João Naves de Ávila, 2121 - Campus Santa \\ Mônica, Bloco 3N, CEP:38402-902, Uberlândia, MG - Brazil, Phone: +55 3432394763 /+55 3432394733
}

\begin{abstract}
This article is aimed at presenting and establishing computational procedures to evaluate refunding requests for damages based on mechanisms that allow the insertion of the problem, coming from direct measurements, in an application for this purpose (APR 2.0 Software). For such, it is described a structure to measure, process, and transfer real-time information on incidents in power system, and its corresponding insertion in the aforementioned software. The basic philosophy is in the direct registration of disturbances, which, until then, had been obtained through computer simulations. Experimental studies are also presented and discussed to illustrate and validate the proposal made.
\end{abstract}

\section{Key words}

Computational application, Refunding request for damages, Disturbances, Data transmission, Real time disturbances measurements.

\section{Introduction}

Technological change has contributed substantially in the design and marketing of modern equipment, especially the electronics ones, found in various sectors of society. Generally, these devices improve the comfort, safety, production, and bring other benefits. However, despite the advantages, many of these products exhibit high dependency on the quality of electricity supply [1].

In fact, the dynamics of a power system caused, among other things, by actions of protective devices, input and output loads of high power, starting of motors, short circuits occurrence, strong presence of non-linear loads, and incidence of lightning strikes cause disturbances and strong impacts on the operational characteristics of many devices [2]. Under the action of these phenomena, which are often treated under the designation of non-ideal conditions of operation, electrical devices are likely to operate inappropriate or, in extreme cases, cause physical injury, thus requiring prompt replacement of parts or product as a whole [3,5].

This situation has provoked an appreciable growth of compensation demands for electrical equipment supposedly damaged because of a non-ideal voltage supply from the utility. The question becomes more relevant when one considers the amount of financial resources involved in the matter.

Thus, it is important the development of mechanisms to establish a systematized procedure, based in science and technology, which yields to an impartial decision about judgments. In this way, there are different possibilities to analyse and provide a final report about a given occurrence. One of this consists in using a computational strategy to evaluate the relationship between typical distribution system disturbances and their propagation up to the end consumer [6].

Given this, the authors have produced, in the past, a software dedicated to support the technical analysis of electrical damage claims from consumers. As a final product of the work carried out, it was created the computational application APR (Analyzer Request for Refunding). It allows playback the computational playback of phenomena occurring in the distribution networks, the conversion of disturbance into dielectric and thermal stresses, and the subsequent comparison with the limits for supportability of the equipment under review, providing, this way, subsidies to issue a technical opinion on the request of refunding $[7,8]$. This procedure consists in the recognition of the occurrence to identify its origin and its computer simulation. The model includes, for the representation of the network, the disturbance source and its spread to the end consumer.

Despite the fact that studies aimed at validating the process have been encouraging, it is worth noting that anomalous cause manifested is, so far, obtained only by computational alternative route. By recognizing the importance of the viability of another strategy for the insertion of the disturbances, the idea of the work summarized in this article arose, which is focused on establishing a procedure to allow the inclusion of the phenomenon occurred via direct measurement.

Within this context, this article describes the mechanisms and procedures for the monitoring of disturbances in electricity distribution networks, transmission of information in real time to a central database, and 
insertion of the phenomenon reported in the APR software.

Once reaching this goal, it is, therefore, evident that the analysis software in question will be flexible in order to offer two ways to reproduce the occurrence. The first one in line with conventional procedures based on computational simulations of the sources of disturbances, and the second one coming from a database of records extracted on-line from the occurrences in the power network.

\section{Design of Measurement and Storage of Information}

The proposal to adapt the APR software for the stated aims in this paper is linked to the use of modern equipment to record the voltage of wave forms. This product is already being sold, which permits the registration of waveforms, point by point, the storage of information of the disturbance occurred in the electrical system under focus, the transmission of information in real time via GSM / GPRS, the formation of a Database at the centre of reception set by the power utility, and, finally, its use for the purposes stated here.

Access to these data can be, for example, made available to the centre of analysis of refunding requests for damages, allowing the user of the APR program to acquire the waveform measures relevant to the associated case of claim for damages. For this, the responsible for analyzing the APR may be in the same physical environment of the database, or simply access them remotely via the Internet. Fig. 1 illustrates the positioning of the meter installed to be positioned in a pre-established place in the energy distribution network.

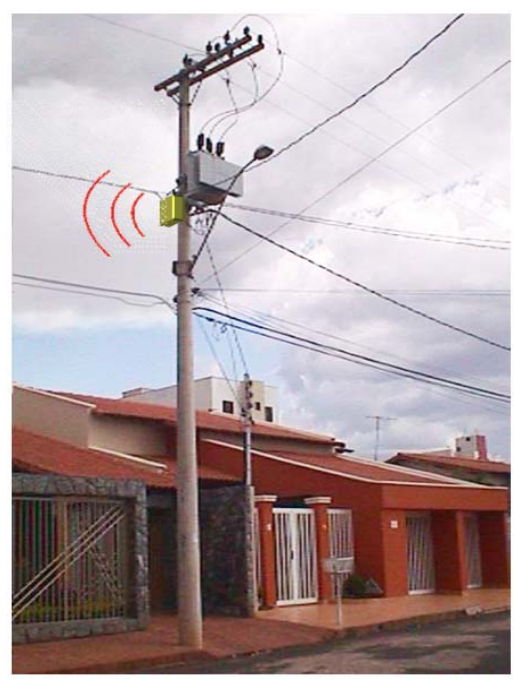

Figure. 1 - Illustration of installation of recorder/transmitter disturbances.

The system used for recording, transmission, and storage of data is illustrated in Fig. 2, which highlights: the point of installation of meters, the transmission of information to the centre of reception, and the centre where they will be stored and where it will be made available the files representing the events manifested in the power network for future use by the APR software.

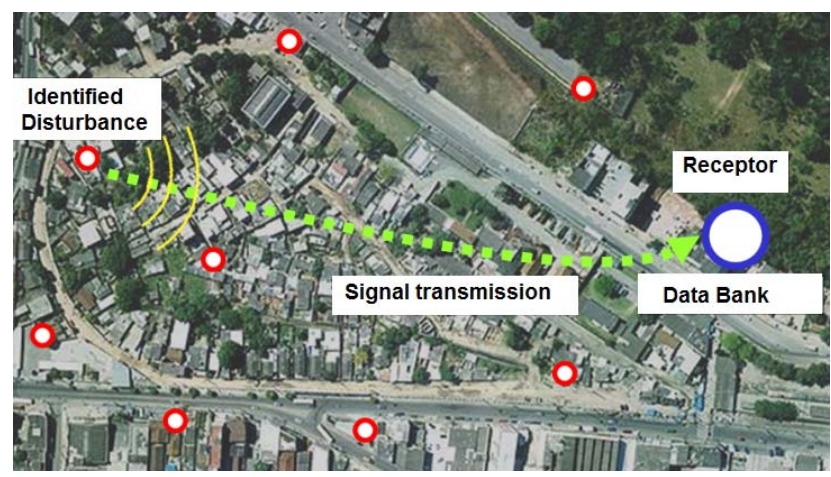

Figure. 2 - Structure of the proposed system for acquisition, transmission, and storage of the signals monitored.

\section{Components of the Process Measurement-Transmission-Storage}

of

The devices that integrate the process under analysis, preferably, should prioritize the use of commercially available resources in the market and also provide the necessary reliability for the purposes pursued here. Within this logic, there was a selection of products with recognized technical assistance in the country, without ignoring other issues, such as: cost, quality, suitability, etc. The following part presents a brief description of a physical structure designed for this work.

\section{A. Recorder of disturbances}

The device illustrated on Fig. 3 corresponds to the remote unit for the acquisition of waveforms of voltages, especially for those moments in which disturbances occur in the distribution networks. In addition to the records, this unit is also responsible for storing the instantaneous values of voltage in its mass memory.

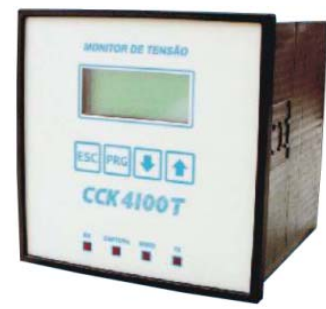

Figure 3 - Recorder of disturbances

The main features of this product are:

- Power supply: 90 to $240 \mathrm{~V}_{\mathrm{AC}}$ with automatic selection of voltage or $125 \mathrm{~V}_{\mathrm{DC}}$;

- Electric Power used by the device: 3 VA;

- Autonomy of 6 hours of operation and 48 hours of data retention in case of power failure;

- Inputs: 3 phases, neutral, and earth;

- Resolution of $0.1 \mathrm{~V}$;

- Measuring range from 0 to $600 \mathrm{~V}$ rms voltage of phase-neutral;

- $0.5 \%$ accuracy;

- 128 samples per cycle; 
- Peaks up to $4000 \mathrm{~V}$ with 100 milliseconds in duration;

- Voltage Transient from 130 microseconds duration;

- $\quad$ Elevation and sags from $1 / 2$ cycle duration;

- Records of events between neutral and earth;

- $\quad$ Serial communication RS 485.

\section{B. Data transmitter}

Via RS 485 serial communication, information from the event recorder is transferred to another system via MODBUS protocol, as seen in Fig. 4. This is coupled to a modem, shown in Fig. 5, via Ethernet connection with TCP / IP. Thus, this unit promotes the transmission of data via cellular networks GSM / GPRS to the company server. It is also important to mention that the transmitted data should be consistent with time intervals that meet user needs and the phenomenon under analysis.

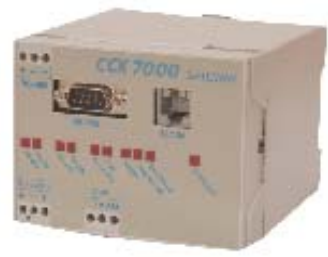

Figure 4 - Converter information of measurement to allow connection to Internet via GSM mobile phone

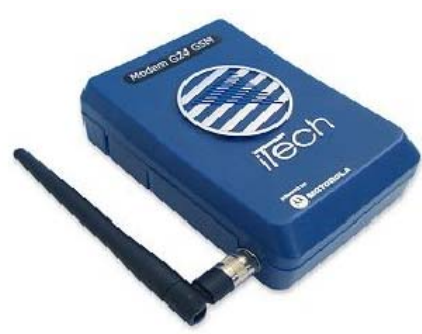

Figure 5 - Product used for data transmission.

\section{Centre of reception}

The data transmitted must be received and recorded in accordance with the date and time of occurrence of the event. This will lead to a database available on the server installed in the centre of informatics in the company. Such information could be readily accessed in its own environment, or via the Internet, as shown in Fig. 6.

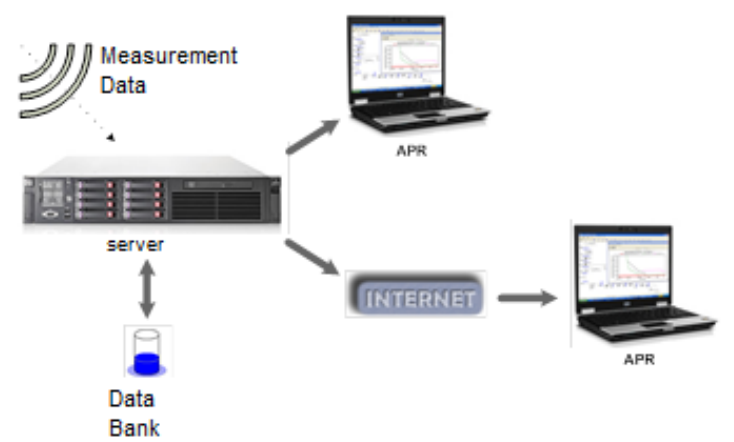

Figure 6 - Storage complex and availability of access to information
Finally, from the information obtained and stored, there should be means for establishing a strategy to adapt the information as it is required for its insertion in the APR software, as detailed in the subsequent section.

\section{Inclusion of Information in the Database in the APR Software}

\section{A. Structure of APR}

Fig. 7 shows the new structure of the APR, with the new form of insertion of the disturbances. The figure includes all the steps contained in the original program and also the strategy for the inclusion of information from the database mentioned above. As can be seen in the block highlighted, this required a new entry for the source of disturbances, thus resulting in the new version of the APR. This software, as can be observed, is likely to keep the performance of disturbances in power network via computational simulation or through records in real time from the measurement files. The dotted arrows indicate processes of internal communication of software, which are independent of actions of the user, while the solid arrows represent direct actions of the operator through the graphical interface, such as the new tool developed here.

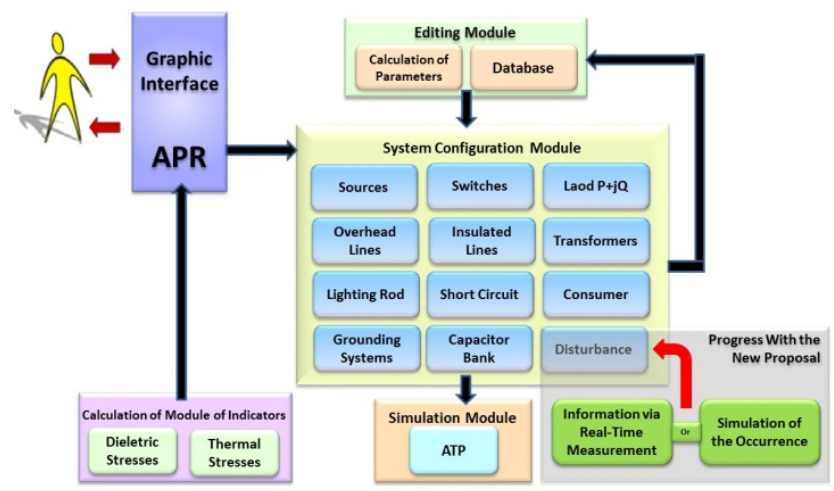

Figure 7 - Structure of APR software with the possibility of insertion of information via measurement

\section{B. Insertion of the disturbance measured in computer simulation}

By accessing the database server at the company, either on the site or via the Internet, the user sees a list with the records of disturbance in this investigated power grid and also the files containing the instantaneous values of voltages, the nature of the phenomenon, the maximum values found, the time of occurrence, etc. Fig. 8 illustrates this information screen.

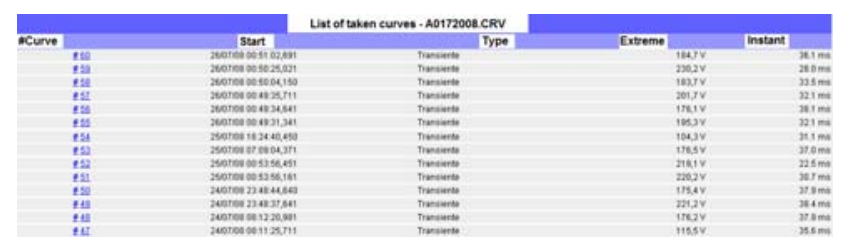

Figure 8 - Example of a data file about the disturbances measured available by the server 
Through a click on the numbers of disturbance chosen, the files of instantaneous values generated by the equipment may be accessed and viewed graphically or in vectors, with information about voltage versus time for each sampling point of the signal. Fig. 9 shows an example of instantaneous values measured for phases $\mathrm{A}, \mathrm{B}$, and $\mathrm{C}$, respectively, and the sampling rate of 128 points per cycle $(60 \mathrm{~Hz})$ with a window of 8 cycles for each phase. Thus, the graph representative of the monitored voltages is shown in Fig. 10. This allows a visualization of the performance of tensions during the time interval used.

\begin{tabular}{|ccc|}
\hline Phase A & Phase B & Phase C \\
$(0.00000,0.1)$ & $(0.00000,-1.0)$ & $(0.00000,-0.1)$ \\
$(0.00013,0.4)$ & $(0.00013,-1.1)$ & $(0.00013,-0.3)$ \\
$(0.00026,0.3)$ & $(0.00026,-1.0)$ & $(0.00026,-0.3)$ \\
$(0.00039,0.0)$ & $(0.00039,-1.0)$ & $(0.00039,-0.2)$ \\
$(0.00052,0.0)$ & $(0.00052,-1.0)$ & $(0.00052,-0.1)$ \\
$:$ &. &. \\
$:$ & $:$ & $:$ \\
$(0.13268,109.5)$ & $(0.13268,63.7)$ & $(0.13268,-167.8)$ \\
$(0.13281,118.4)$ & $(0.13281,54.0)$ & $(0.13281,-166.9)$ \\
$(0.13294,126.2)$ & $(0.13294,44.4)$ & $(0.13294,-165.1)$ \\
$(0.13307,132.3)$ & $(0.13307,, 35.2)$ & $(0.13307,-162.4)$ \\
$(0.13320,136.9)$ & $(0.13320,26.6)$ & $(0.13320,-158.5)$ \\
& & \\
\hline
\end{tabular}

Figure 9 - Example of instantaneous information about available tensions on the server

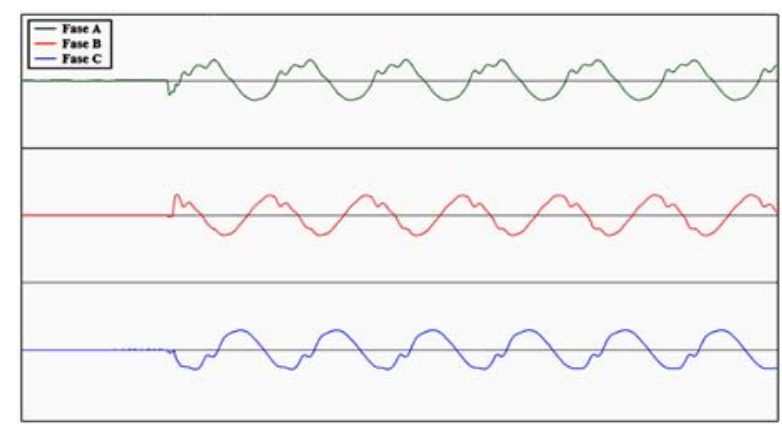

Figure 10 -Example of waveforms of voltages measured and available on the server

Aiming to illustrate the mechanisms used to transfer the information obtained (the example of the tensions mentioned above), it is presented below, the steps for the transfer of the data file to a computing environment, which, in line with the ultimate goal of this research, consists in the ATP platform.

For both, the authors developed a model of voltage source for this program (ATP) in the programming language used by it. To facilitate the conversion of signal data measured in voltage sources, it was used the "Pointlist" command, available from the MODELS tool. This feature was employed for the insertion and external data processing in the ATP software.

Through the procedures highlighted, the end result of this development is shown, illustratively, in Fig. 11, where it is highlighted the waveforms inserted and played by this software. Comparing the results shown in this figure with graphics available on the server (Fig. 10), there is a good correlation between the waveforms obtained; a fact that validates the procedure used.

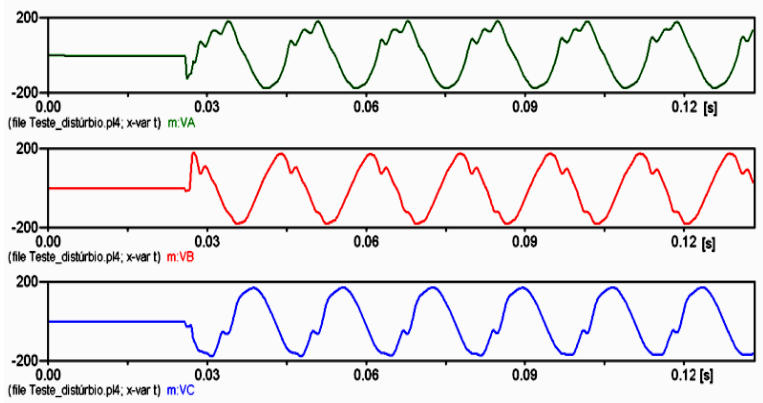

Figure 11 -Example of waveforms of voltages inserted in the ATP software

\section{Test of Performance in Laboratory}

In order to ratify the performance of all of the measurement system and proposed simulation, laboratory tests were performed. The experimental setup used is shown in Fig. 12, which shows, among other equipment, a programmable HP6834A three phase source for the generation of voltage signals representative of typical phenomena manifested in power grids, which are, in this environment, recorded on a digital oscilloscope.

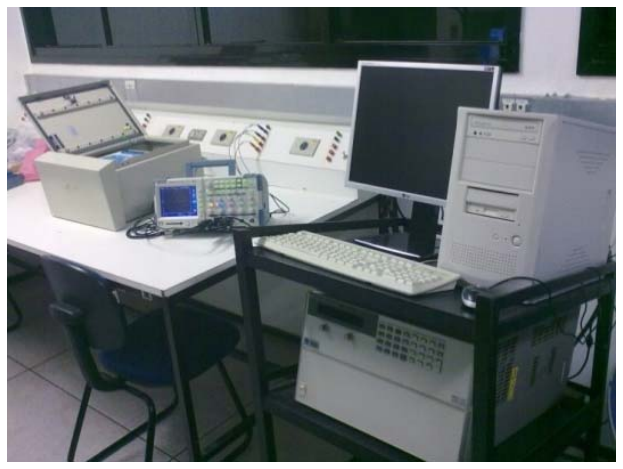

Figure 12 - Laboratory arrangement used for testing the performance of the proposed system

Although different operating situations have been evaluated, for the purpose of this study, only two conditions are presented, as explained in Table I.

TABLE I. Cases Studied

\begin{tabular}{|c|c|}
\hline Case & Features \\
\hline $\begin{array}{c}\text { 1- Single } \\
\text { Phase Short } \\
\text { Circuit }\end{array}$ & Rated voltage of $127 \mathrm{~V}, 60 \mathrm{~Hz} ;$ \\
Short-circuit in phase B; \\
Event of 3 cycles.
\end{tabular}

\section{A. Case 1: Single-Phase Short Circuit}

The first case, associated with the network performance during the occurrence of a short-circuit phase-ground, as it is know, generates a sag in phase B and an elevation for 
the two other phases. Fig. 13 illustrates the waveform generated by the programmable source and which is representative of the phenomenon in question.

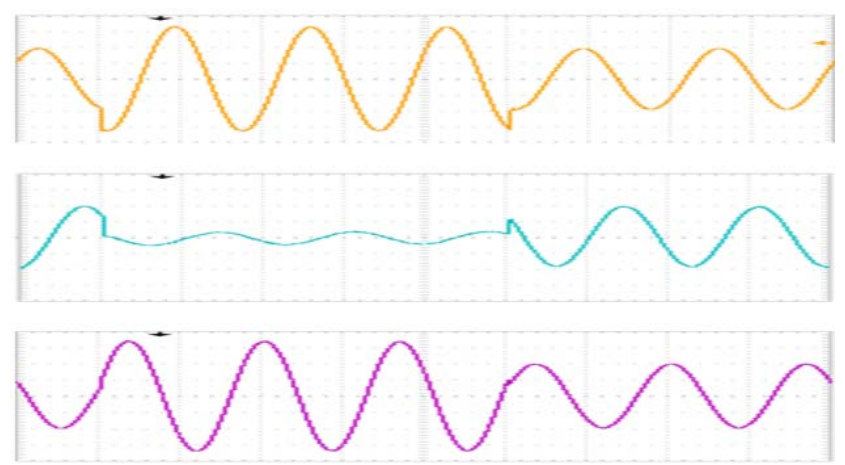

Figure 13 - Waveforms of the tensions produced by the source and recorded by the oscilloscope - short circuit.

Once performed the measurements by the structure presented in this paper, the results available on the server corresponds the waveforms shown in Fig. 14. These are presented with forms of values corresponding to those produced by the programmable source.

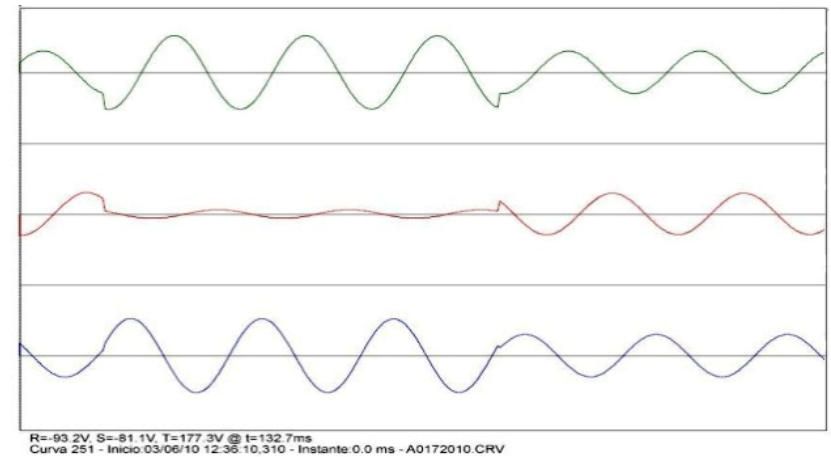

Figure 14 -Waveforms of voltages stored and available on the server - short circuit

Finally, the resources developed via MODELS permitted the transfer of the phenomenon to the ATP platform. Fig. 15 shows the results obtained, which clearly shows a good correlation with the magnitudes generated by the source and made available by the server.
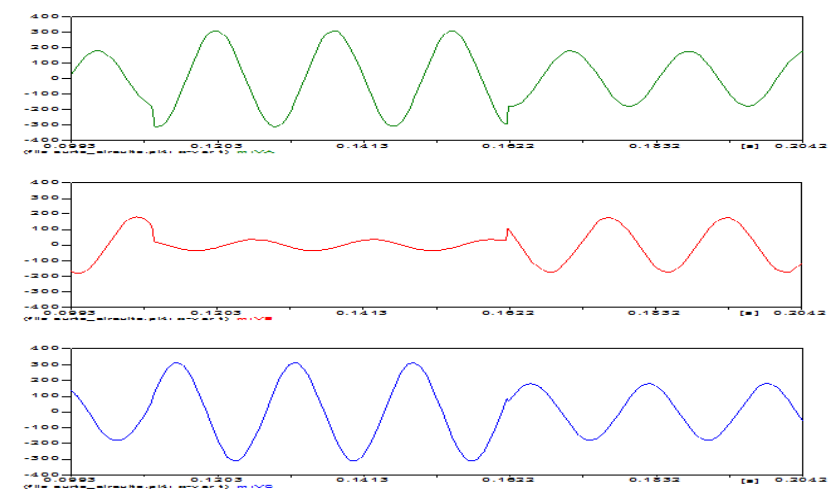

Figure 15 -Waveforms of voltages inserted and available in the ATP - short circuit

\section{B. Case 2: Oscillatory transient voltage}

This situation comprises in another assessment of performance, repeating the procedures described above; however, this time, it focus on the phenomenon corresponding to a transient voltage, probably the one energizing a capacitor bank.

In line with the same sequence used previously, Figs. 16, 17 , and 18 show the waveforms of voltage, produced by the source, available on the server, and, finally, the tensions inserted in the ATP.

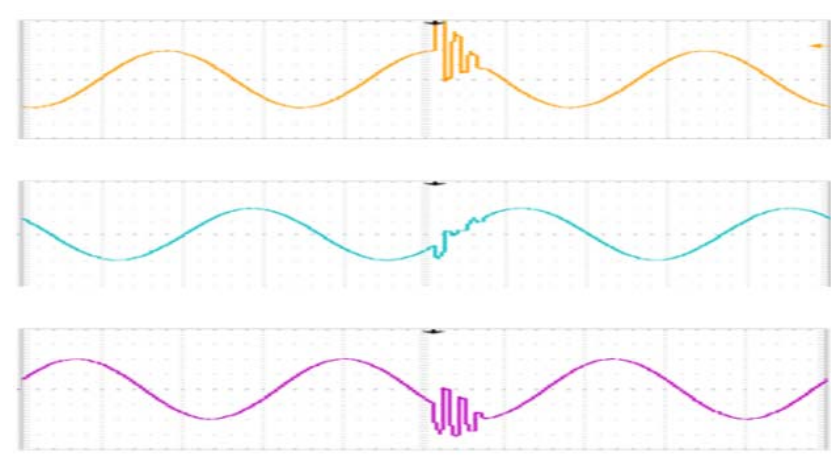

Figure 16 -Waveforms of the tensions produced by the source and recorded by the oscilloscope - oscillatory transient

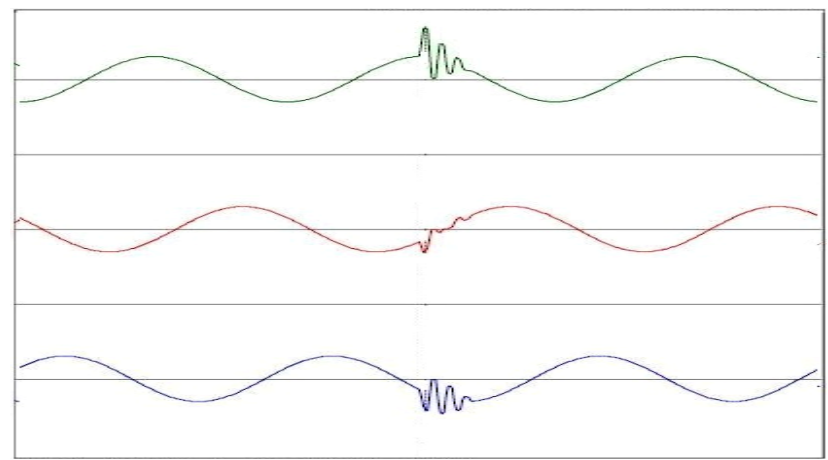

Figure 17 - Waveforms of voltages stored and made available on the server - oscillatory transient

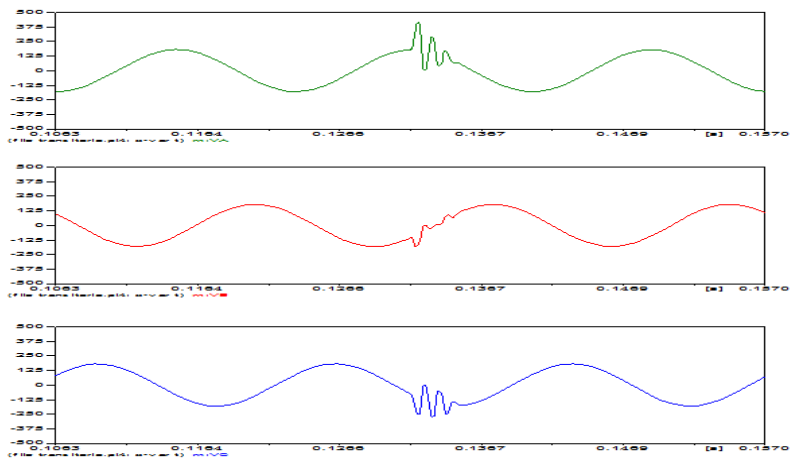

Figure 18 - Waveforms of voltages available and included in the ATP - oscillatory transient

The results for the situation associated with a transient voltage, again, confirm the procedures and show that the strategy employed is appropriate to the goals outlined for this work. 


\section{Conclusions}

This paper presented the development of a proposal for the monitoring and recording of disturbances, which can occur in distribution networks, in order to improve the process of examining claims for damages through the APR software. The bulk of the activities is in the structure of hardware-software for the record, transmission, and storage of information related to disorders manifested in the electrical complex and aimed, as its final objective, to the inclusion in this database analysis software to refund requests for damages.

From the proposed structure designed and assembled, the authors proceeded, in sequence, to the development of means that would enable the integration of information monitored and made available on a server, on the ATP platform based of simulations and the rendering of the APR software. For this, it was used the MODELS tool in accordance to what was presented.

Computational and experimental studies have demonstrated the success of the proposal on the issue of data registration and transmission, formation of banks of information on voltage produced in the laboratory, and, ultimately, their insertion into the ATP.

From these results, it is demonstrated the feasibility of employing real-time records for evaluative studies addressed here.

\section{Acknowledgment}

The authors acknowledge the financial support received from the Brazilian Councils FAPEMIG, CAPES, and $\mathrm{CNPq}$ for the doctorate and master scholarship which resulted in this paper.

\section{References}

[1] R. C. Dugan, M. F. McGranaghan., S. Santoso., H. W. Beaty, Electrical Power Systems Quality, 2nd Edition. USA: McGraw-Hill, 2003.

[2] M. H .J. Bollen, Understanding Power Quality Problems: Voltage Sags and Interruptions, Piscataway, IEEE Presss, 2000.

[3] H. R. P. M. Oliveira, N. C. Jesus, M. L. B. Martinez, "Avaliação do Desempenho de Equipamentos Eletrodomésticos Durante Ensaios de Sobretensões", XVIII SNPTEE, Curitiba/PR, Outubro de 2005.

[4] M. D. Teixeira, R. L. Araújo, L. M. Ardjomand, , A. R. Aoki, N. S. R. Quoirin, I. Wunderlich, "Acceptable Power Quality Limits to Avoid Damages in Appliances", WSEAS Transactions on Circuits and Systems, Issue 5, vol. 4, May 2005.

[5] K. Ermeler, W. Pfeiffer, D. Schoen, M. Schocke, "Surge Immunity of Electronic Equipment", IEEE - Electrical Insulation Magazine, Vol. 14, 1998.

[6] A. S. Jucá, "Avaliação do Relacionamento entre Consumidores e Concessionárias na Solução de Conflitos por Danos Elétricos: Proposta de adequação", Tese de Doutorado em Engenharia Elétrica, Escola Politécnica da Universidade de São Paulo, USP, São Paulo/SP, 2003.

[7] J. C. de Oliveira, M. V. B. Mendonça, C. E. Tavares, I. N. Gondim, A. C. Delaiba e F. O. Teixeira, "Aplicativo Computacional para Suporte Técnico à Análise e Parecer de Pedidos de Ressarcimento”, III SBSE, Belém/PA, Maio de 2010.

[8] C. E. Tavares, J. C. de Oliveira, M. V. B. Mendonça, A. C. Delaiba, R. M. T. Silva, "An Approach for Consumers Refunding Analysis Associated to Voltage Disturbances and Equipment Damages”, Revista Eletrônica de Potência SOBRAEP, vol. 13, $\mathrm{N}^{\mathrm{o}}$ 1, Fevereiro de 2008. 